$B D X-613-70$

CONF-650608-1

\title{
A NEW DEVELOPMENT IN POLYURETHANE ELASTOMER PROCESSING WHICH REDUCES CRACK SUSCEPTIBILITY AND BUBBLE ENTRAPMENT
}

\author{
April, 1965 \\ By Donald D. Oswald \\ THE BENDIX CORPORATION \\ Kansas City Division
}

\section{LEGAL NOTICE}

This report was prepared as an account of Government sponsored work. Neither the United States, nor the Commission, nor any person acting on behalf of the Commission:

A. Makes any warranty or representation, expressed or implied, with respect to the accuracy, completeness, or usefulness of the information contained in this report, or that the use of any information, apparatus, method, or process disclosed in this report may not infringe privately owned rights; or

B. Assumes any liabilities with respect to the use of, or for damages resulting from the use of any information, apparatus, method, or process disclosed in this report.

As used in the above, "person acting on behalf of the Commision" includes any employee or contractor of the Commission, or employee of such contractor, to the extent that such employee or contractor of the Commission, or employee of such contractor prepares, disseminates, or provides access to, any information pursuant to his employment or contract with the Commission, or his employment with such contractor. 
A NEW DEVELOPMENT IN POLYURETHANE ELASTOMER PROCESSING WHICH REDUCES CRACK SUSCEPTIBILITY AND BUBBLE ENTRAPMENT

By Donald D. Oswald

THE BENDIX CORPORATION

Kansas City Division

\section{INTRODUCTION}

The space age has brought about ever increasing demands on the electronic packaging engineer to develop equipment capable of withstanding greater and greate $r$ acceleration environments. The design criteria must include both electrical and mechánical considerations. Electrical components and circuitry must be designed to perform certain functions and adequate mechanical support must be provided to protect the electrical system from damage during periods of high acceleration. The supporting media must be three things: a good insulator, rigid enough to give adequate support, and resilient enough to withstand shock loading without fracture. Polyurethane elastomers used as encapsulants satisfy these three requirements. The encapsulant must, however, be free of cracks and entrapped bubbles. The tendency of polyurethane elastomers to crack and entrap bubbles during cure is a major problem. Both conditions tend to reduce insulating properties and structural strength.

Crack formation during cure can be theoretically attributed to two conditions. One is high stress concentration areas due to design configuration, and the second is microscopic size bubbles from which cracks can originate when subject to cure stresses. This theory proposes that there is a relationship between crack formation and bubble entrapment. Elimination of bubbles from the encapsulant before cure 
would then solve the entrapped bubble problem and reduce the cracking.

\section{A. Bubble Entrapment Problem}

The physical complexity of electronic assemblies leaves many potential bubble traps and gene rally requires the encapsulation process to be performed at some pressure less than atmospheric to aid in filling. At reduced pressures the amount of entrapped air, due to assembly configuration, is reduced. Bubbles that are inherent in the encapsulant due to the compounding process are expanded by the reduced pressure, which increases the buoyant force and causes them to rise to the surface and escape more readily. This is true only within certain practical pressure-time limits. The low limit of pressure is controlled by the amount of volume increase that can be tolerated when filling a mold. The lower the pressure the greater the volume increase due to expanding gases. The time that the pressure can remain reduced without permanently trapping expanded bubbles is limited by the progress of reaction.

Not all of the expanded bubbles escape, because the viscosity rise due to reaction prevents the smaller ones from rising to the surface. These bubbles are reduced in size when the pressure is raised back to atmospheric, but nevertheless remain in the encapsulant; in most cases they are small enough to be tolerable. Also, at reduced pressures:some gases emerge from solution, and do not go back into solution when the pressure is raised.

In theory, the bubbles that remain suspended in the encapsulant after the pressure is raised do not dissolve or escape because of the following:

1. The solubility of liquids for gases is partially dependent on the chemical properties of the liquid. Since the chemical 
properties are changing quite rapidly during the early stages of reaction, the solubility for gases may be decreasing with the state of reaction.

2. The solubility of liquids for gases: is partially dependent on the degree to which the liquid is already saturated with gases.

3. The "pot-life" of the encapsulant is short, and there is insufficient time for all the bubbles to escape before progress of reaction renders them immobile.

B. Solution to Bubble Entrapment

1. Degas the components of the encapsulant at a pressure level below the encapsulation pressure, prior to compounding. This eliminates outgassing after compounding, disregarding gases evolving as products of reaction. The degassing also increases the solubility for additional gases, by decreasing the degree of saturation of the compound. Therefore, the bubbles remaining after the pressure is raised can more readily go into solution, and not remain as voids in the encapsulant.

Using this line of reasoning, a process was developed to degas the polyurethane prepolymer as completely as possible without decomposing the prepolymer.

2. Maintain a low pressure during the encapsulation process only long enough to fill the mold, allowing as many bubbles as possible to escape during the fill. This will use only a portion of the "pot-life"! before the pressure is raised, and will not trap any expanded bubbles. 


\section{PROCESS}

The degree to which a particular fluid is degassed, pressure and temperature being constant, is largely dependent on the depth of fluid and time the fluid is exposed to the pressure-temperature environment: To keep the depth and time within practical limits the prepolymer is processed through a modified molecular distillation unit. The basic process consists of heating the prepolymer in the 55-gallon drum shipping container, transferring it from the container into a temperature controlled vacuum chamber, where the material is wiped into approximately a .001 inch thick film while being exposed to a vacuum of approximately 150 microns of mercury. Wiping the fluid into a thin film allows the volatiles and dissolved gases to readily escape. When the prepolymer enters the chamber it flashes into a head of foam with violent outgassing taking place: As the prepolymer progresses through the chamber the outgassing becomes less and less, until at the exit there is essentially no outgassing. Laboratory analysis of the prepolymer indicates that nitrogen is the basic element being removed. (Note: Nitrogen is used by the manufacturer to convey the prepolymer through the manufacturing process.) From the vacuum chamber the prepolymer is transferred to a storage reservoir, where the material is available to the manufacturing departments for direct use or for packaging to send to stores.

The molecular distillation equipment used for degassing consists of three integral systems: a vacuum system, a material transfer system, and a heating system. (Refer to Figure 1.)

The material transfer system is composed of four gear pumps, apparatus to spread the prepolymer into a thin film, transfer devices to route it through the vacuum chamber, and the associated valving and piping. The chamber wall and all pumps, piping, and valves exposed to the prepolymer are made of stainless steel. The wipers are made of Teflon. 
The vacuum system consists of a roughing pump in series with a diffusion pump and a cold trap. The system is designed for operation within the range of 25 microns of mercury and atmospheric pressure. A vacuum of one micron of mercury can be obtained with this equipment, - if so desired.

The cold trap is necessary to protect the diffusion pump from volatiles that would contaminate the pump oil and render the pump non functional. The cold trap utilizes dry ice and isopropyl alcohol as the cooling medium, maintaining the temperature at approximately $-98^{\circ} \mathrm{F}$. The cold trap is particularly necessary for start-up of equipment, following solvent purge of the material transfer system.

The heating system consists of a drum preheater for the prepolymer, heaters for the pipes, valves, and pumps, and a means of heating the vacuum chamber. The drum of prepolymer is heated to and maintained at approximately $140^{\circ} \mathrm{F}$. The lines, valves, and pumps are maintained at approximately the same temperature as the prepolymer in the drum, to keep the viscosity at a practical pumping consistency. The degassing surface in the vacuum chamber is maintained at $180^{\circ} \mathrm{F}$. An even dis tribution of heat is maintained on the degassing surface by means of a jacket of heat transfer fluid heated by band heaters. To protect the fluid against burning next to the band heaters and to aid heat transfer to the degassing surface, the fluid is periodically made to boil. The boiling is accomplished by subjecting the fluid to a vacuum, which is controlled by a thermoswitch in conjunction with a solenoid-operated vacuum control valve.

Prior to any extended shutdown of the equipment, it is necessary to solvent-purge the material system of all residual prepolymer. For this purpose the dressing equipment has a recycling solvent-purge system. Purging is accomplished by recycling solvent (trichlorethane) 
through the system for a period of time; to guarantee complete suspension of prepolymer in the solvent. The solvent is then discarded and replaced with clean solvent which remains in the system until the next. start-up. At the time of start-up the solvent is again recycled for a short time and then discarded.

Operating instructions for the degassing equipment are programmed on audio-magnetic tape. There are four separate programs detailing information for start-up and shutdown of equipment under different conditions. There is an audio amplifier and tape deck mounted on the machine. Located on the opposite side is a switch and speaker interconnected to the amplifier system. The extra switch is for convenience of the operator in calling for instruction, when a subsequent operation takes him to the side opposite the amplifier.

This form of operating instruction has proven very effective, particularly from the standpoint of operation sequencing. It also reduces the training time to break-in new operators.

\section{EVALUATION (Experimental Program)}

In the past, considerable work has been done developing techniques and apparatus to serve as a means of evaluating the crack tendency of encapsulation compounds. Several devices have been developed which afford some empirical method of comparison of the tendency of rnmpositions to crack when cured about rigid objects. Examples of typical devices used for this purpose are described in Military Specification MIL-C-16923A (30 January 1952) and in U. S. Patent 2, 681,901 (Wiles and Elam, June 22, 1954). These devices work well with the rigid epoxy formulations but they do not work with the polyurethane elastomers. The stress conditions of the devices are not critical enough to crack the elastomers. 'It was therefore necessary to develop a means of cracking the polyurethane elastomer during cure. It was desired to have an inexpensive, readily available apparatus that would give a measure of both bubble entrapment and crack 
tendency in the same sample. The apparatus that satisfied these requirements was a 5/8-inch diameter glass test tube with a $1 / 2$-inch diameter, spiral wound, wire bristle, wire handle brush (Figure 2). The brush, having fine bristles extending from the center out in a helical pattern, provided a great number of potential bubble traps. The bubble traps and the helical configuration confined in the test tube provided the necessary stress conditions to crack the polyurethane elastomer.

Numerous samples were made using the test tube, wire brush, and prepolymer that had not been processed through the degassing equipment. All samples were cracked when examined after cure; The cracks in the elastomer did exhibit different patterns. Some samples had cracks that were coincident with the helix of the brush and other samples had cracks that were perpendicular to the helical pattern. (Refer to Figures 3 through 7.) This indicated that the stress pattern varied between samples. The different patterns could not be correlated with different physical properties of the prepolymer, because samples made from the same batch of material exhibited both types of cracks. However, the majority of samples did exhibit the same types of cracks within a given batch. Sizes of cracks within a batch were also approximately the same. Crack tendency then can be rather crudely categorized by size of cracks, or crack configuration. Also, bubble entrapment can be similarly graded by size and number of bubbles in a certain volume of elastomer.

An experiment was then set up using polyurethane that had been degassed and some that had not been. Holding everything else constant, several samples of each were made using the brushes and test tubes. To minimize the possibilities of bias, the technician performing the experiment was not made aware of the difference in samples. After cure, the samples were inspected; the samples madefrom non-degassed material were all cracked and numerous bubbles were evident, while 
samples made from the degassed material were not cracked and practically bubble-free. (Refer to Figure 8.)

An interesting phenomenon was the fact that many of the test tubes, containing the degassed elastomer samples, cracked during cure. (Refer to Figure 9.) None of the test tubes containing non-degassed material cracked. The cause may be attributed to one or more of the following:

1. The adherence properties of the elastomer to glass is improved by degàsing.

2. The non-degassed material fails below the breaking strength of the glass tube.

3. The cure-stress pattern' is different between the degassed and non-degassed materials.

The formulation of polyurethane used for the evaluation was 100 parts by weight of prepolymer to 11 parts by weight of $4,: 4^{\prime}$ : Methylene-Bis $(2$ - Chloroaniline $)=($ MOCA $)$.

The formulation process was:

1. Weigh 200 grams of prepolymer into a polyethylene container.

2. Heat prepolymer to $225^{\circ} \mathrm{F}$.

3. Evacuate prepolymer at 1 millimeter of mercury, until bubbling stops.

4. Stabilize temperature of prepolymer at $185^{\circ} \mathrm{F}$. (approximately 30 minutes).

5. Melt granular MOCA at $225^{\circ} \mathrm{F}$, in pyrex container.

6. Evacuate MOCA at 1 millimeter of mercury, until bubbling ceases.

7. Stabilize MOCA at $225^{\circ} \mathrm{F}$. 
8. Weigh 22 grams of MOCA into Adiprene.

9. Immediately mix Adiprene and MOCA by stiring vigorously with metal spatula for one minute.

10. Pour 2 inches of Adiprene in each of four test tubes.

11. Insert metal brushes in test tube. (Brushes had been ultrasonically cleaned in Freon T. F.)

12. Set test tubes and brushes in vacuum chamber and evacuate for three minutes at 3 millimeters of mercury.

13. Cure in $160^{\circ} \mathrm{F}$ : oven for four hours.

14. Cool to room temperature, and inspect.

\section{CONCLUSION .}

The brush and test tube approach to evaluating the feasibility of degassing polyurethane prepolymer satisfied our needs.

The test samples provided positive results that the crack susceptibility of polyurethane elastomers was greatly reduced as a result of degassing. Also, the samples of degassed material indicated a definite reduction in the number of trapped bubbles. Correlating the results tends to substantiate the theory that crack tendency and bubble entrapment are related. Comparing typical physical characteristics of elastomer samples, made from degassed and non-degassed prepolymer, gives additional verification of the relationship. For typical physical properties see Table I; the change in tensile strength is the most notabie. Values as high as 7000 psi have been measured.

The manufacturing departments, using polyurethane prepolymer for encapsulation of electrical and electronic assemblies, have noted a definite decrease in scrap (due to bubbles and cracks) since introduc-: tion of degassed material. 
Assemblies that were difficult to encapsulate under a vacuum, because of problems other than voids, can now be encapsulated at atmospheric conditions and still stay within the void size tolerances. 
TABLE I. TYPICAL AVERAGE PHYSICAL PROPERTY VALUES

Physical Properties Tested

Tensile Strength, PSI

Modulus, $300 \%$, PSI

Elongation at Break \%

Hardness, Shore "A".

Compression Set, \%

Tear Strength, ASTM-D-624

Die-C, lb/in.
Average Values

Degassed Non-Degassed

$6000-U p \quad 4500$

$2200 \quad 2200$

$400 \quad 450$

$.92 \quad 92$

$30 \quad 40$

$\therefore 50 \quad 450$ 


\section{TITLES OF ILLUSTRATIONS}

Figure

1

2

3

4. Helical Crack

$5 \quad$ Helical Crack

$6 \quad$ Helical Crack

$7 \quad$ Perpendicular Crack

8. Bubble-Free Sample, from Degassed Material

9 Cracked Test Tube (Contained Degassed Sample) 


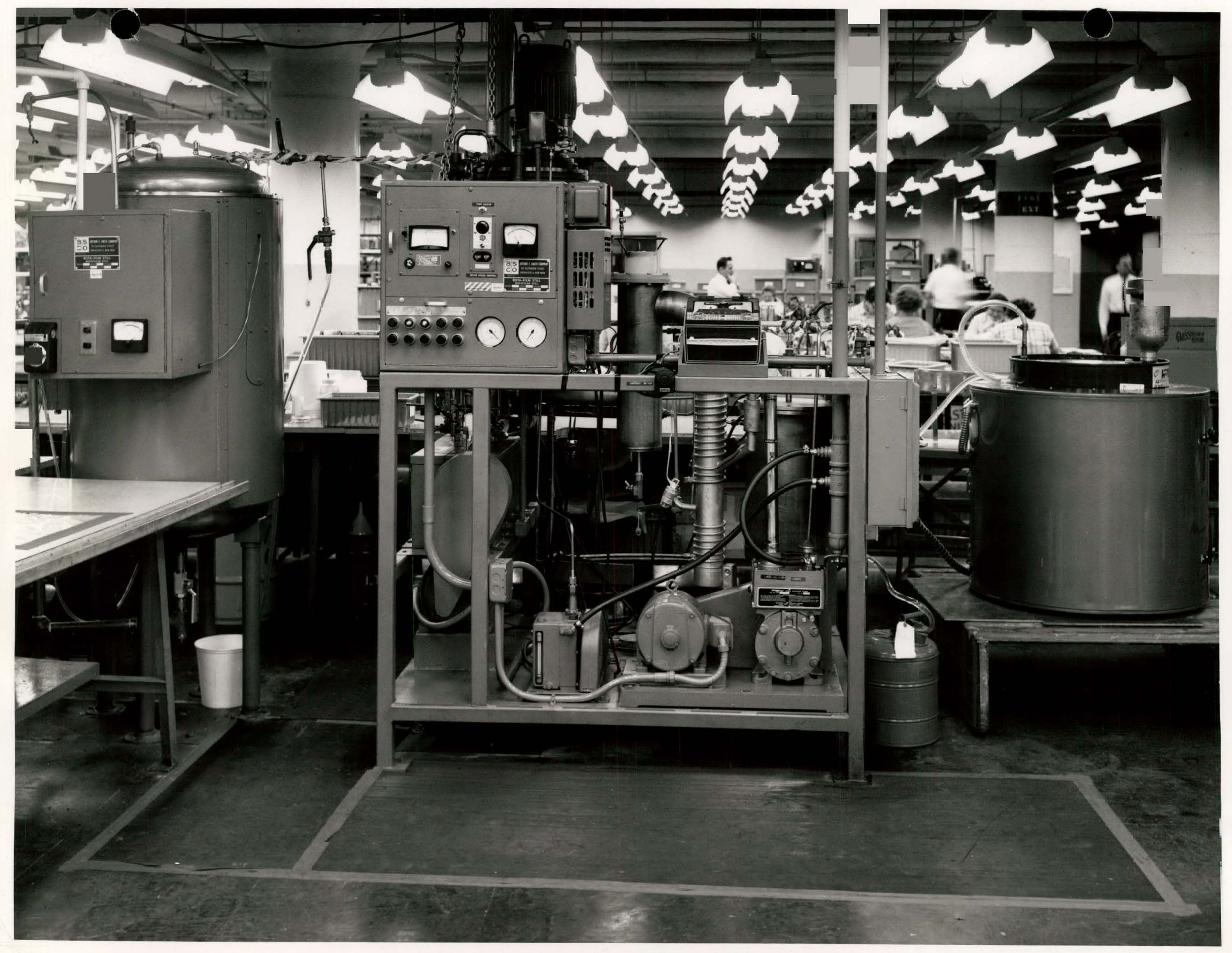


40792

MAR I 9965 
О - 


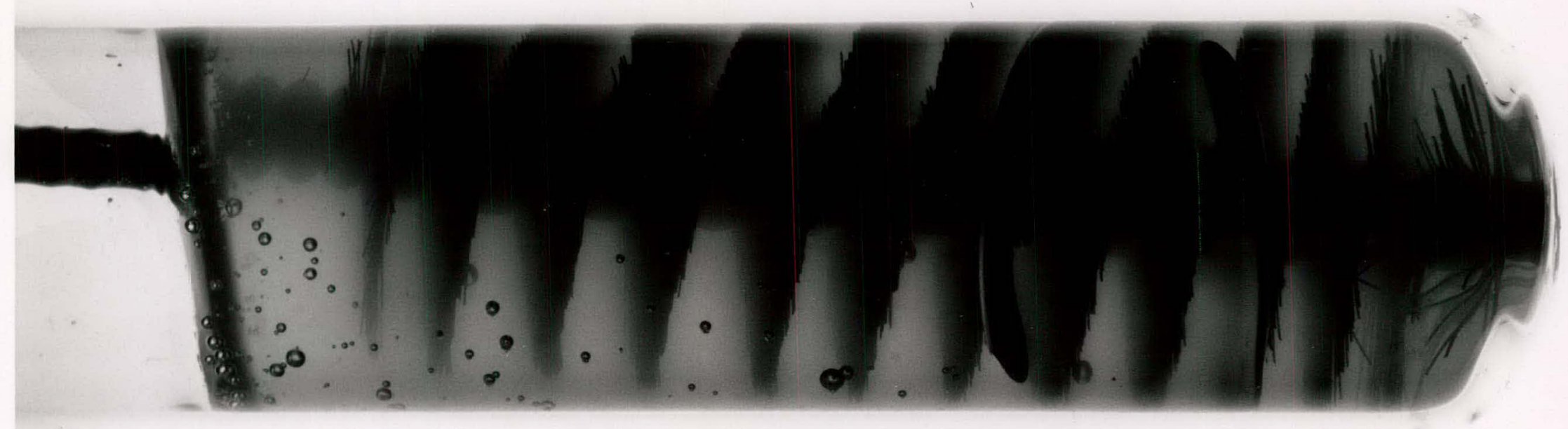


P $407 \cdots$

MAR 9- 2055 


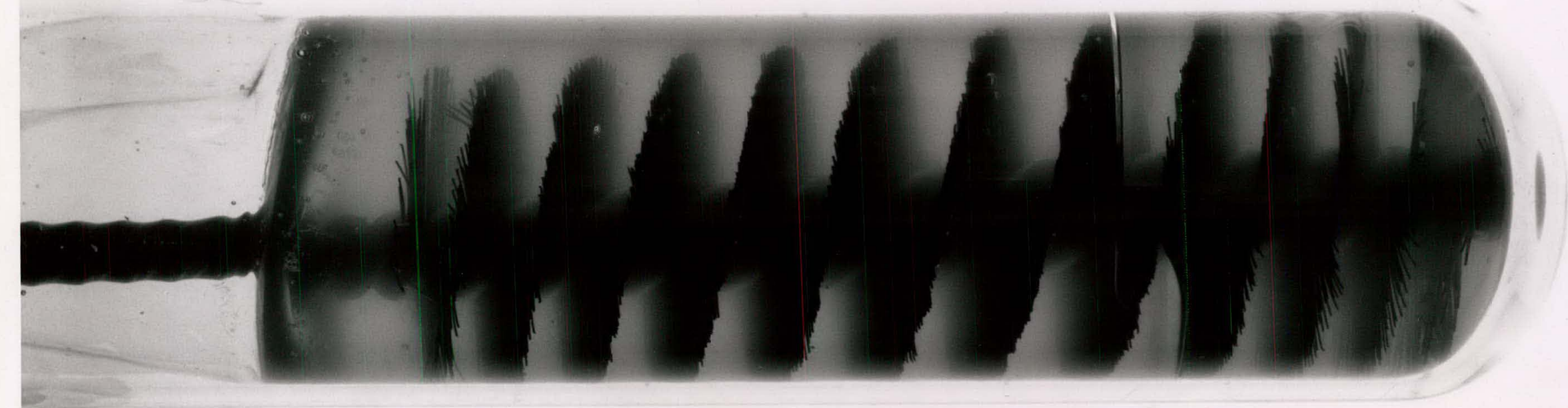




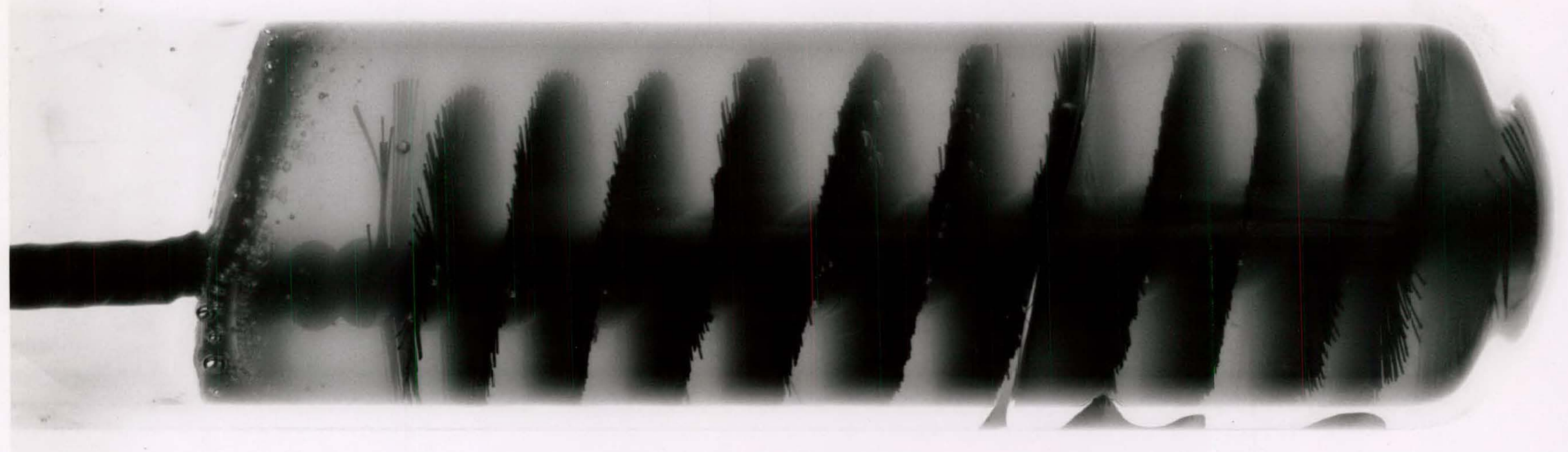




\section{2}




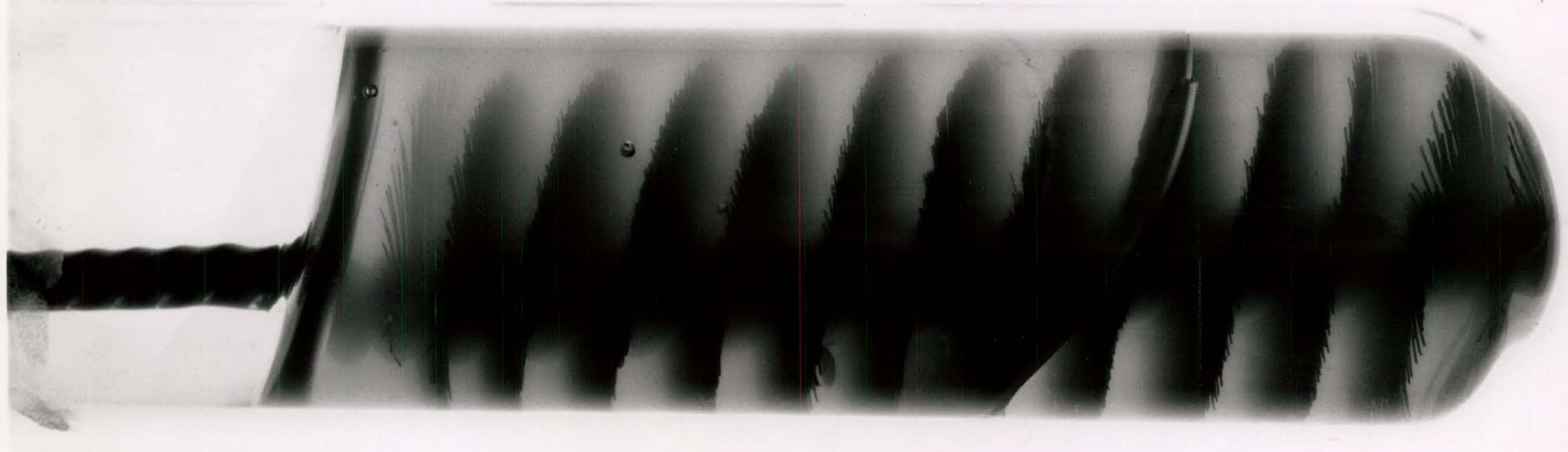


p 40723

MAR $9-9965$ UNCLASSIFIED 


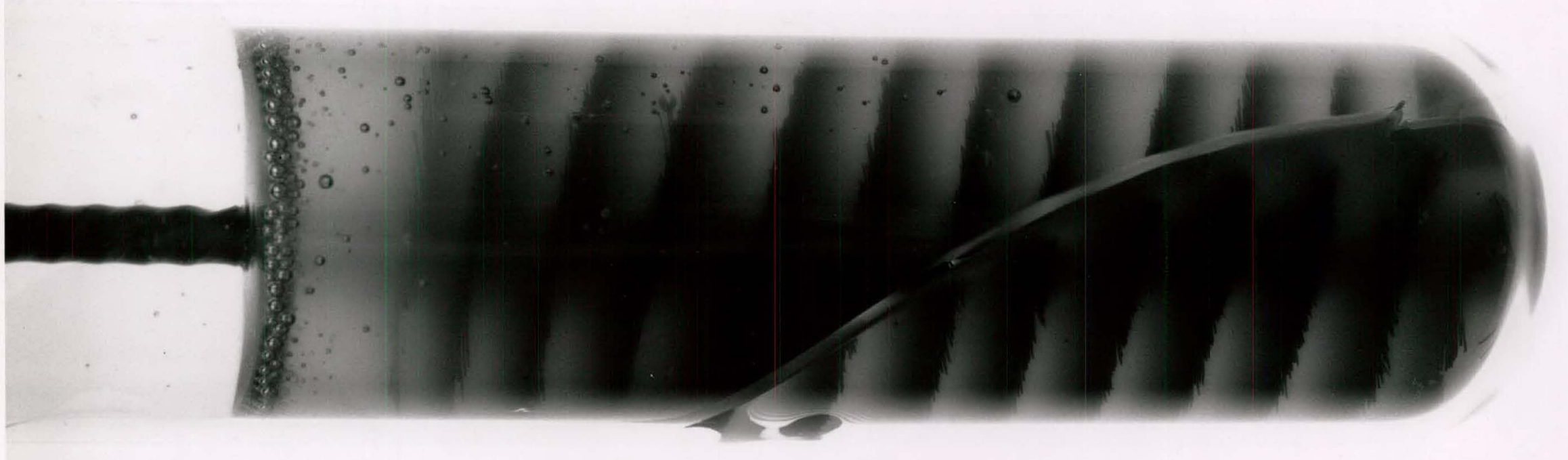




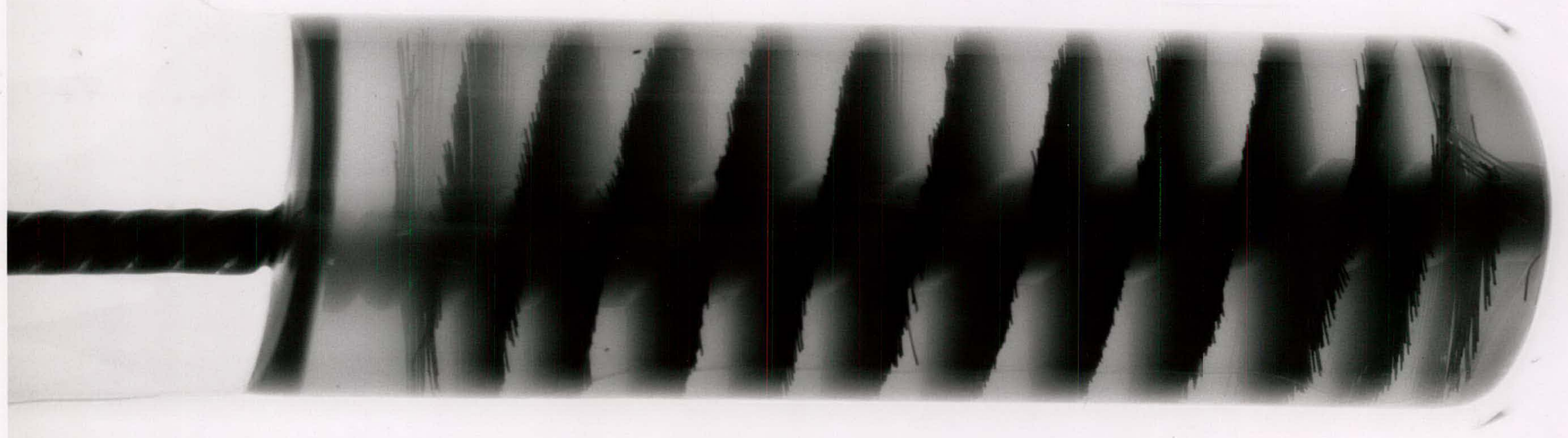


MAR 9- 1965 


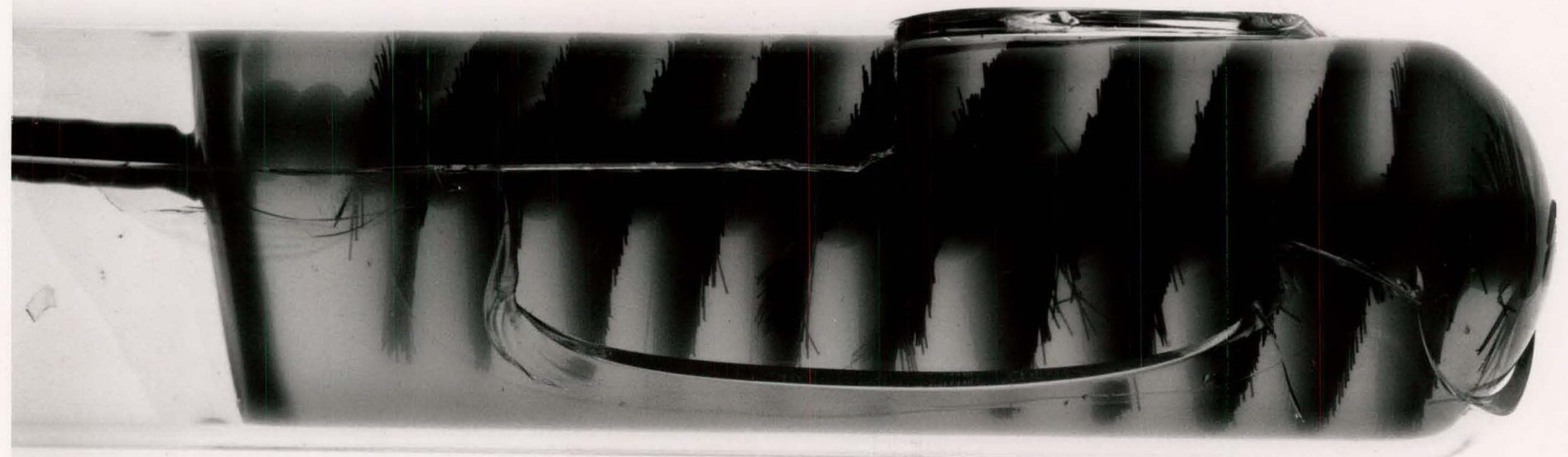




\section{Pu0725}

MAR $9-2655$

\section{UNCLASSIFIED}

$\sqrt{3}$

8 